\title{
Intervenção pedagógica para o desenvolvimento de habilidades de tradutores em formação sobre questões de textualidade via abordagem Ler para Aprender
}

\author{
Pedagogical intervention via the Reading to Learn approach for the development of in-training translators' \\ abilities on textuality aspects
}

Teresinha Penaforte Vieira

Universidade Estadual do Ceará - UECE - Ceará- Brasil

\section{Pedro Henrique Lima Praxedes Filho}

Universidade Estadual do Ceará - UECE - Ceará- Brasil

\begin{abstract}
Resumo: Este artigo relata um estudo de intervenção pedagógica desenvolvido com tradutores em formação na Universidade Estadual do Ceará, no qual foi adotada a abordagem pedagógica sistêmico-funcionalista da Escola de Sydney (ROSE; MARTIN, 2012; entre outros) com algumas adaptações para a atividade tradutória. O estudo teve como foco o desenvolvimento da subcompetência bilíngue e metarreflexão dos participantes (HURTADO ALBIR, 2005; PACTE, 2003) quanto aos aspectos relativos à tessitura textual (HALLIDAY; MATTHIESSEN, 2014; MARTIN, 1992; entre outros). O corpus, constituído por respostas a questões de atividades pedagógicas e comentários feitos em entrevistas, foi analisado qualitativamente, abordando-se o produto e o processo tradutórios. Os resultados apontaram uma significativa elevação no nível de subcompetência bilíngue dos participantes e também no nível de sua capacidade metarreflexiva sobre os aspectos abordados, elevando suas habilidades de leitura, de produção e revisão textual e, por conseguinte, suas habilidades tradutórias.
\end{abstract}

Palavras-chave: Intervenção pedagógica. Escola de Sydney/LSF. Estudos da tradução. Subcompetência bilingue. Metarreflexão.

\begin{abstract}
This article aims at reporting a study carried out with undergraduate students majoring in translation in English language at the State University of Ceará, adopting the systemic-functional pedagogical approach of Sydney School (ROSE; MARTIN, 2012; and others) with some adaptations for the translation activity. The study focused on the development of bilingual sub competence and meta-reflection of in-training translators (HURTADO ALBIR, 2005; PACTE, 2003) on textuality aspects (HALLIDAY; MATTHIESSEN, 2014; MARTIN, 1992; among others). The corpus, consisting of the answers to the questions of the Pre/Post-test and pedagogical activities as well as the comments made during interviews, was analyzed qualitatively, approaching both translation product and process. The results showed a significant increase in the participants' level of bilingual sub competence and, also in the level of their meta-reflexive capacity as for the taught textual aspects which raised their skills at reading, textual production and revision, and, consequently, at translation.
\end{abstract}

Keywords: Pedagogical intervention. Sydney School/LSF. Translation studies. Bilingual sub competence. Meta-reflection. 


\section{INTRODUÇÃo}

Como atividade de natureza multilíngue e interdisciplinar, a tradução demanda do tradutor habilidades diversas e conhecimentos linguísticos e extralinguísticos (MUNDAY, 2008). Apesar dos avanços tecnológicos que propiciam ferramentas digitais para facilitar a tarefa tradutória, ainda há dificuldades relacionadas à tradução de determinados textos, devido às possibilidades de alteração de conteúdo experiencial e mensagem do texto-fonte (PAGANO, 2012).

Por conta dos múltiplos aspectos envolvidos na tradução de um gênero textual, o tradutor precisa refletir sobre suas escolhas, tendo em vista que esse gênero realizará um determinado processo sociossemiótico para um público diferente. Isso implica que o profissional da tradução precisa estar atento às diferenças culturais e ao papel da língua na construção do diálogo com esse público por intermédio do texto traduzido em determinada situação social. Dessa forma, a conscientização do tradutor sobre o potencial de escolhas e a plausibilidade delas dentro de um determinado contexto social influencia a qualidade do seu trabalho e, por conseguinte, o seu perfil profissional. Tais habilidades dele exigidas podem ser desenvolvidas através do estudo de estratégias de tradução e da realização de atividades práticas voltadas para os vários aspectos que envolvem os textos em relação de tradução (KIM, 2010; MAGALHÃES; ALVES, 2006; VASCONCELLOS; PAGANO, 2005; entre outros).

Nesta perspectiva, o estudo (VIEIRA, 2018), do qual deriva este artigo, realizou uma intervenção pedagógica voltada para tradutores em formação inicial de língua inglesa do Curso de Letras - Inglês do Centro de Humanidades da Universidade Estadual do Ceará (UECE). Nela, fizemos uso de algumas estratégias pedagógicas baseadas em gêneros da Escola de Sydney, especificamente da metodologia 'Ler para Aprender' (Reading to Learn-R2L) (CHRISTIE, 2011; MARTIN; ROSE, 2007; 2005; ROSE; MARTIN, 2012; entre outros), com algumas adaptações (descritas na Subseção 2.3).
Esse estudo objetivou investigar o desenvolvimento da subcompetência bilíngue e, em consequência, da metarreflexão de tradutores em formação, no par linguístico português-inglês, durante a intervenção pedagógica. Lembramos que a subcompetência bilíngue é uma das subcompetências que constituem a competência tradutória (PACTE, 2003) e a metarreflexão refere-se ao processo de elaboração de pensamento reflexivo sobre a tarefa tradutória, visando a tomada de decisões conscientes (ALVES, 2005).

Neste artigo, apresentamos algumas estratégias pedagógicas da metodologia Ler para Aprender' (MARTIN; ROSE, 2005; ROSE; MARTIN, 2012; entre outros) utilizadas em Vieira (2018), mostrando como elas foram adaptadas para o trabalho com tradutores em formação. Destacamos também alguns resultados proporcionados por meio do uso, em sala de aula, dessas estratégias de ensino teóricopráticas, visando fomentar a conscientização desses participantes sobre as influências do contexto social nas escolhas realizadas em relação a diversos aspectos dos textos escritos (fonte e alvo).

Esses textos foram abordados com base na concepção de texto como instância de um gênero que tem sua função em determinado contexto social (ao realizar processos sociossemióticos) e analisados com foco nos recursos de tessitura textual: coesão estrutural (o sistema de tema) e não estrutural (gramatical e lexical) (HALLIDAY; MATTHIESSEN, 2014; HALLIDAY; HASAN, 1989; MARTIN, 1992; entre outros). Assim, enfatizamos a visão de texto como um todo, em que sistemas distintos atuam simultaneamente na construção do tecido textual, levando em conta a função dos textos nos contextos (cultural e situacional) em que circulam (VIEIRA, 2018).

Este artigo consta de três seções, incluindo esta seção introdutória. A seguir, apresentamos o desenvolvimento e, por fim, as considerações finais. 


\section{DESENVOLVIMENTO}

Nesta seção, apresentamos algumas considerações sobre os pressupostos teóricos que nortearam a pesquisa ora relatada: os estudos da tradução, a abordagem pedagógica 'Ler para aprender' e a Linguística Sistêmico-Funcional (LSF). Discorremos também sobre o percurso metodológico e alguns resultados do estudo.

\subsection{Considerações sobre os estudos da tradução}

O estudo, desenvolvido na interface entre os estudos da tradução e a LSF, foi fundamentado em trabalhos numa perspectiva descritiva e/ou linguísticofuncionalista da tradução (HALLIDAY, 1992; MATTHIESSEN, 2001; VASCONCELLOS; PAGANO, 2005; entre outros). Halliday (1992) concebe a atividade tradutória como uma "criação de significados quiada"1 (HALLIDAY, 1992, p. 15) (grifo do autor) pelas escolhas realizadas no texto-fonte. Alinhado com essa perspectiva, Matthiessen (2001, p. 64) postula que a '“tradução' não é um reflexo passivo do texto-fonte; é um ato criativo de reconstrução dos significados do texto-fonte como significados no 'texto-alvo'”2. Defendendo que a tradução de um texto-fonte é uma entre as possíveis retextualizações desse texto, Vasconcellos e Pagano (2005, p. 198) argumentam que, ao ter consciência desse fato, o tradutor em formação poderá "enxergar a tradução como uma atividade de construção de significados, acontecendo em uma configuração situacional diferente daquela da textualização inicial". Dessa forma, evidencia-se, conforme a LSF, a dimensão paradigmática/sistêmica de língua (como potencial de recursos) passando o texto-alvo a ser concebido como uma entre as alternativas possíveis para a tradução de um textofonte, o que permite ao tradutor selecionar, dentre as escolhas disponíveis, aquela que seja a mais viável na cultura-alvo (HALLIDAY, 1992).
A competência tradutória $(\mathrm{CT})$ é definida como "conhecimento especializado, integrado por um conjunto de conhecimentos e habilidades, que singulariza o tradutor e o diferencia de outros falantes bilíngues não tradutores" (HURTADO ALBIR, 2005, p. 19). A CT qualifica o tradutor para desempenhar sua atividade de forma consciente, mediante a reflexão e o monitoramento do seu fazer tradutório (HURTADO ALBIR, 2005). Segundo o modelo holístico PACTE (2003), essa competência é constituída pelas subcompetências bilíngue, extralinguística, estratégica, instrumental e de conhecimentos sobre a tradução e, ainda, pelos componentes psicofisiológicos (memória, percepção, criatividade e outros). Adotamos essa perspectiva de desenvolvimento da CT e estudamos a tradução como produto e processo. Contudo, por limitação de tempo, restringimo-nos à subcompetência bilíngue.

Para Hurtado Albir (2005), o conhecimento sobre aspectos relacionados a gêneros textuais, relações contextuais, coesão e coerência textuais são indispensáveis para o tradutor exercer sua atividade satisfatoriamente. A intervenção pedagógica focou especialmente nos conhecimentos relativos às relações contextuais e sua influência na construção dos gêneros e aos aspectos da tessitura textual (coesão estrutural e não estrutural), visando o desenvolvimento da subcompetência bilíngue e metarreflexão de tradutores em formação. Ressaltamos que a subcompetência bilíngue se refere a conhecimentos operacionais (pragmáticos, sociolinguísticos, textuais e léxico-gramaticais) e a 'metarreflexão' é concebida como o processo de elaboração do pensamento reflexivo sobre operações que estão sendo realizadas, o que poderá proporcionar um monitoramento eficiente do processo tradutório, levando o tradutor a perceber problemas e tomar decisões conscientes para solucioná-los (ALVES, 2005).
[...] guided creation of meaning. Esta e demais traduções são de nossa autoria.

\footnotetext{
2 [...] "translation" is not a passive reflection of the original; it is a creative act of reconstruing the meanings of the original as meanings in the "target".
} 


\subsection{Considerações sobre a abordagem pedagógica sistêmico-funcionalista da Escola de Sydney e alguns aspectos da LSF discutidos na intervenção pedagógica relatada}

Para Christie (2011), há diversas abordagens que tratam da pedagogia baseada em gênero e todas têm proporcionado contribuições significativas para a educação. Dentre elas, selecionamos a abordagem da Escola de Sydney, especialmente sua versão 'Ler para Aprender' (MARTIN; ROSE, 2005; 2007; ROSE; MARTIN, 2012). Nossa opção deve-se à sua orientação sistêmico-funcionalista; logo, suas estratégias de ensino focam na função social como fator determinante quanto às escolhas em cada texto instanciador de um dado gênero, a ser usado em determinada situação em uma dada cultura. Essa ideia de 'escolhas' se apoia na concepção hallidayana de língua como potencial de recursos distribuídos em eixos paradigmáticos ou sistemas, estando à disposição do usuário para a construção de significados orientados a desempenhar funções em contextos sociais específicos (HALLIDAY; MATTHIESSEN, 2014, p. 20). Então, essa abordagem é congruente com a concepção de tradução como retextualização (VASCONCELLOS; PAGANO, 2005).

Além disso, levamos em conta o longo envolvimento da LSF com o ensino de línguas e os trabalhos realizados por pesquisadores como Jim Martin e David Rose em programas de letramento na Austrália. Trata-se de um ensino colaborativo, com orientação estratégica e produção em grupo e individual. Para esses autores, um ensino descritivo e produtivo propicia oportunidades para 0 desenvolvimento de conhecimento sobre a língua e também sobre como usá-la com propósitos distintos (MARTIN; ROSE, 2005; 2007; entre outros). Defendemos que essa abordagem poderá levar ao desenvolvimento da capacidade metarreflexiva de tradutores em formação.
Consideramos, ainda, o fato de que essa é uma abordagem ampla que, no ensino de línguas, abarca questões relativas ao contexto e suas variáveis (campo, relações e modo) e à construção dos significados ideacionais, interpessoais e textuais (HALLIDAY; MATTHIESSEN, 2014). Assim, partindo da noção de gêneros escritos com fins sociais específicos, essa abordagem focaliza as implicações de duas dimensões organizacionais da língua segundo a LSF: a instanciação e a estratificação. Destacamos que a perspectiva organizacional (hallidayana) de língua em dimensões - estrutura (ordem sintagmática), sistema (ordem paradigmática), estratificação, instanciação e metafunções (HALLIDAY; MATTHIESSEN, 2014, p. 20) - propicia a compreensão da sobreposição de tipos diferentes de significados e formas, o que é relevante para as atividades de leitura, de produção textual e de tradução.

Em relação à instanciação, "cada texto é uma instância do sistema linguístico inteiro, e cada traço ou aspecto da língua que se apresenta num texto é uma instância de uma das opções no sistema linguístico"3 (MARTIN; ROSE, 2007, p. 3). Assim, a abordagem 'Ler para Aprender' parte da língua em uso, ou seja, do texto/instância, mas enfatiza também a relevância da assimilação dos sistemas da língua pelos aprendizes no sentido de prepará-los para que possam produzir os gêneros em conformidade com as práticas sociais do seu contexto. Portanto, trata-se de uma pedagogia que se diferencia do ensino tradicional.

Em relação à estratificação, destaca-se a relação entre língua, com seus estratos internos, e contexto, visto como estrato extralinguístico. De forma semelhante à língua, o contexto também pode ser descrito do ponto de vista da instanciação: parte-se da cultura inteira de determinada comunidade em direção à determinada situação interacional específica. Logo, o contexto de cultura é o mais amplo e o contexto de situação é o mais específico e imediato (uma

\footnotetext{
${ }^{3}$ each text is an instance of the entire language system, and each language feature in a text is an instance of one of the options in the language system.
} 
instância da cultura) e determina os tipos de texto que circulam em tipos distintos de situação social (HALLIDAY; MATTHIESSEN, 2014). O contexto de situação é definido por três variáveis, as quais são realizadas pelo estrato da semântica e este, por sua vez, é realizado pelo estrato da lexicogramática (HALLIDAY, 1989). Sendo assim, torna-se essencial o reconhecimento dos padrões contextuais, semânticos e léxico-gramaticais de um gênero. A Figura 1 ilustra essa relação.

\section{Figura 1 - Estratos da língua}

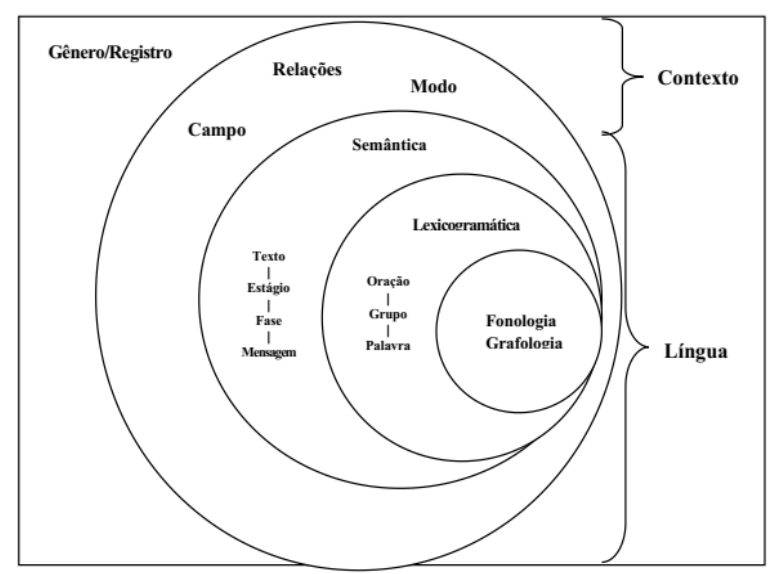

Fonte: Adaptada de Martin e Rose (2007, p. 2) e Martin e Rose (2005, p. 257).

Como colocado anteriormente, no estudo ora relatado, exploramos a noção de contexto de situação, focando nas suas variáveis - campo, relações e modo do discurso -, a partir das quais, segundo Martin e Rose (2007), o aprendiz deve reconhecê-lo. O campo diz respeito à natureza da atividade sociossemiótica em curso (a atividade social, o objetivo comunicativo e o assunto tratado). As relações concernem aos papéis discursivos dos participantes envolvidos na situação, às relações de poder e de afeto, à duração das relações e a todo o conjunto de relações socialmente significativas referentes à situação. $O$ modo do discurso refere-se ao papel desempenhado pelo texto em seu contexto: o papel da língua (constitutivo ou ancilar), o canal (fônico ou gráfico), o meio (oral ou escrito), o modo retórico (informativo, didático ou outros) (HALLIDAY, 1989; HALLIDAY; MATTHIESSEN, 2014). Como da relação texto-contexto resultam diferenças e similaridades entre os textos (HALLIDAY, 1989), destacamos a relevância de compreender essa inter-relação nas atividades de leitura, de produção textual e de tradução.

A metodologia sistêmico-funcionalista baseada em gênero, inicialmente denominada 'Ciclo da Escola de Sydney', era voltada para a produção do texto escrito. Essa metodologia aborda os gêneros em três etapas: 'Desconstrução', 'Construção Conjunta' e 'Construção Individual'. Na 'Desconstrução', os alunos, juntamente com o professor, analisam um texto (uma instância-modelo do gênero a ser produzido), discutem aspectos como contexto de cultura e de situação, estágios (segmentos previsíveis que compõem a estrutura de um gênero) e características léxicogramaticais de cada estágio. A 'Construção Conjunta' é uma etapa desenvolvida pelos alunos, juntamente com o professor, na qual ocorre a geração e seleção de ideias para a produção de um texto escrito (instanciador do gênero discutido anteriormente). Esta é uma etapa interativa e de grande importância devido ao compartilhamento de conhecimentos, dúvidas e soluções de problemas. Na última etapa, a 'Construção Individual', espera-se que os aprendizes estejam preparados para, sem ajuda, produzir outros textos pertencentes ao gênero estudado e para refletir criticamente sobre o seu propósito (ROSE; MARTIN, 2012; ROSE, 2007). A Figura 2 ilustra esse modelo.

Figura 2: Ciclo da Escola de Sydney 


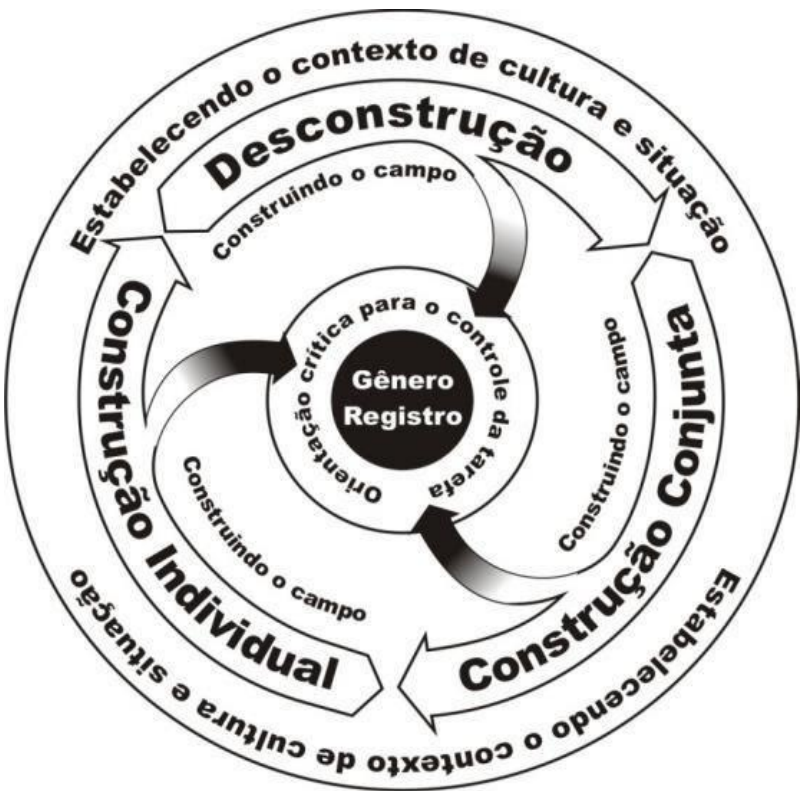

Fonte: Adaptada de Martin e Rose (2007, p. 8).

Essas atividades podem levar os aprendizes à reflexão crítica sobre as questões contextuais (campo, relações e modo) e a função social do gênero, bem como a se familiarizarem com os significados a serem construídos. As duas primeiras fases, além de propiciarem a discussão sobre a estrutura genérica e as características léxico-gramaticais dos estágios, abrem espaço para a introdução de outros temas ou temas transversais (MARTIN; ROSE, 2007). Com novas ideias acrescentadas ao 'Ciclo de Sydney', advindas dos trabalhos de David Rose e outros pesquisadores, surgiu a metodologia do programa de letramento 'Ler para Aprender' (MARTIN; ROSE, 2005; 2007; ROSE, 2007; ROSE; MARTIN, 2012; entre outros).

A metodologia 'Ler para Aprender' ampliou as estratégias de aprendizagem dos padrões da língua escrita e incluiu atividades para desenvolver também a habilidade de leitura, que passou a ser concebida como etapa inicial e fundamental para a escrita (MARTIN; ROSE, 2005). Ressaltamos que essa abordagem contempla, em parte, a aprendizagem de habilidades relativas à atividade tradutória, pois o fazer tradutório requer tanto a habilidade de leitura como a de produção textual e outras. Nessa abordagem, além das características gerais do gênero e dos estágios que o compõem, analisam-se, ainda, as fases (segmentos menos estáveis dentro de cada estágio em que a variável campo do contexto de situação é desenvolvida) e as mensagens contidas nas orações de cada fase de um texto que instancia o gênero (ROSE, 2007). Rose (2007) assevera, ainda, que,

[c]omo ocorre na escala de hierarquias gramaticais [oração, grupo, palavra (acréscimos nossos)], a relação entre gêneros, estágios, fases e mensagens não é apenas de composição, mas também de realização. Um gênero é realizado por seus estágios, os estágios, por suas fases e as fases, por suas mensagens ${ }^{4}$ (ROSE, 2007, p. 4).

A metodologia 'Ler para Aprender' aborda um gênero em três etapas que, por sua vez, subdividem-se em duas subetapas/atividades, conforme descrevemos a seguir:

a) 'Desconstrução' / 'Preparação para a Leitura';

- 'Preparação para a Leitura': nesta subetapa, o professor faz um roteiro oral sobre a construção da variável campo do gênero em discussão, especificando função social e forma de realização, identificando estágios, fases e mensagens e oferecendo suporte para as atividades subsequentes,

- 'Leitura Detalhada': nesta subetapa, é realizada a leitura do texto. Depois, o professor pode orientar os alunos a identificar e discutir o significado de construções específicas (construções não familiares) dentro de cada complexo oracional ou oração de um trecho curto, sendo essa uma atividade opcional, mas, nela, podem ser discutidos vários assuntos, como grupos nominais e verbais, conectivos, entre outros. Portanto, ela pode proporcionar oportunidades para a

realised by its stages, stages by their phases, and phases by their messages. 
apropriação de conhecimentos diversos conforme 0 nível linguístico/de conhecimento linguístico da turma.

b) 'Construção Conjunta';

- 'Preparação para a Reescritura': nesta subetapa, os alunos extraem do texto (em discussão) itens lexicais e fraseados com informações-chave e os escrevem em um lado do quadro (uma atividade cooperativa de seleção e anotação de dados importantes e de geração de ideias para a 'Reescritura'),

- 'Reescritura Conjunta': nesta subetapa, os alunos escrevem, um por vez, o texto na outra parte do quadro, retirando as ideias das notas tomadas na etapa anterior, enquanto 0 professor atua como coordenador, indicando novas construções (se necessário) e apontando inadequações, entre outras orientações.

c) 'Construção Individual'.

- 'Reescritura Individual': nesta subetapa, os alunos produzem um texto semelhante, podendo fazer uso das anotações da fase anterior e ainda receber o suporte do professor ou de algum colega,

- 'Produção Independente': nesta subetapa, os aprendizes assumem o controle da tarefa, realizam pesquisas e produzem textos que instanciam o gênero já estudado, mas realizando um campo diferente (cartas, recontos e outros já estudados).

Essas etapas ou subetapas não são fixas; portanto, podem ser adaptadas (excluídas ou retomadas). Podem ser utilizadas também com textos mais longos, e, neste caso, deve-se fazer as adaptações necessárias conforme o gênero, o objetivo do estudo e as necessidades da turma (MARTIN; ROSE, 2005; 2007; ROSE, 2007; ROSE; MARTIN, 2012).

Por se tratar de atividades sobre a língua, defendemos que as atividades de 'Preparação para a Leitura', 'Leitura Detalhada', 'Preparação para a Reescritura' e 'Reescritura Individual' possivelmente propiciam 0 desenvolvimento da capacidade metarreflexiva dos aprendizes. A Figura 3 ilustra este ciclo.

Figura 3 - Ciclo de atividades da metodologia 'Ler para Aprender'

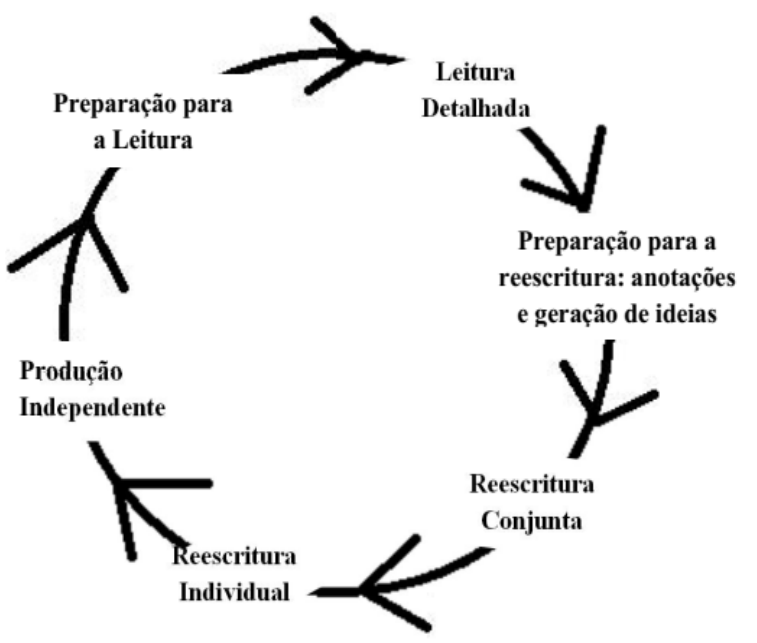

Fonte: Adaptada de Martin e Rose (2005, p. 261).

Vimos que a pedagogia 'Ler para Aprender' trabalha a produção escrita a partir da leitura. Além disso, trata-se de uma visão ampla de leitura, cuja análise parte do contexto social, passa pela estrutura genérica (estágios, fases e mensagens) e chega até às unidades menores dos textos (grupos e palavras) (ROSE; MARTIN, 2012). Entendemos que essa perspectiva de leitura pode levar a uma compreensão abrangente da construção dos significados nos textos.

Foi feito uso de partes dessas estratégias da abordagem 'Ler para Aprender' para mediar o ensino dos recursos relativos à tessitura textual de textos em relação de tradução na intervenção pedagógica realizada em Vieira (2018). Por termos lidado com alunos de curso superior, durante uma disciplina focada na atividade tradutória, foram feitas algumas adaptações, as quais serão apresentadas na subseção seguinte. 


\subsection{Percurso Metodológico}

A intervenção realizada com tradutores em formação, com foco no desenvolvimento da subcompetência bilíngue e metarreflexão, explorou os conceitos teóricos da LSF relativos à tessitura textual, associando a teoria à prática na realização de análises e traduções de textos. Nas atividades, foram abordadas as noções de contexto, gênero, processos sociossemióticos e sistemas de coesão estrutural (sistema de tema) e não estrutural (gramatical e lexical) (HALLIDAY; MATTHIESSEN, 2014; MARTIN, 1992; entre outros). A intervenção ocorreu durante o semestre letivo 2016.2 numa turma de bacharelandos em tradução que estavam cursando a disciplina 'Tópicos em tradução de textos escritos' do Curso de Letras do Centro de Humanidades da UECE. Todos tinham proficiência em língua inglesa, mas tinham pouca experiência em tradução e estavam cursando o quinto semestre do curso; então, foram considerados tradutores novatos. Foram escolhidos quatro participantes (P1, P2, P3 e P4), os quais assinaram o Termo de Consentimento Livre e Esclarecido. A pesquisa foi submetida ao Comitê de Ética em Pesquisa da UECE e aprovada conforme o Parecer 1874766.

$\mathrm{Na}$ abordagem dos conteúdos, utilizamos algumas estratégias da metodologia 'Ler para Aprender' (ROSE; MARTIN, 2012), com algumas adaptações voltadas para a atividade tradutória e para o grupo de tradutores em formação. A Figura 4 ilustra o ciclo de atividades adaptado para a pesquisa.
Figura 4 - Ciclo de atividades da metodologia 'Ler para Aprender' adaptado para a atividade tradutória

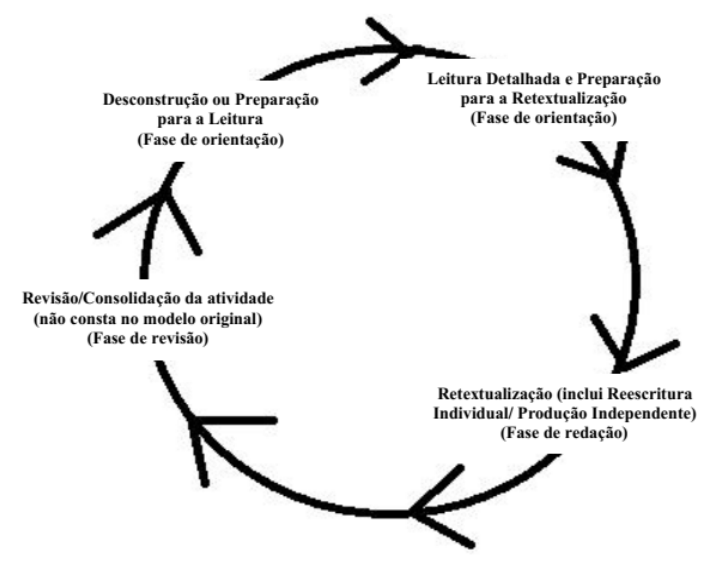

Fonte: Adaptada de Martin e Rose (2005, p. 261).

A Figura 4 mostra que as atividades 'Leitura Detalhada' e 'Preparação para a Reescritura' foram condensadas em apenas uma etapa: 'Leitura Detalhada e Preparação para a Retextualização'. As duas primeiras etapas do modelo adaptado foram utilizadas na análise inicial dos textos fonte (correspondendo à fase de orientação do processo tradutório: leitura/interpretação e discussão de determinados aspectos relacionados aos textos em cada situação social). Por sua vez, as atividades de 'Reescritura Individual' e 'Produção Independente' foram unificadas em uma única atividade de retextualização de textos-fonte (correspondendo à fase de redação no processo tradutório ou produção do texto-alvo). A atividade de 'Reescritura Conjunta' (conforme o modelo original) foi suprimida. A supressão se justifica visto que as duas primeiras etapas do modelo adaptado foram feitas em grupo, o que significa dizer que as análises e as discussões sobre o gênero, contexto e outros aspectos textuais realizadas ao longo de ambas contemplaram o compartilhamento, entre os participantes, de ideias, informações, opções de escolhas para a reconstrução de significados e outras questões. Essa decisão foi tomada durante o desenvolvimento das atividades, sendo, ainda, avaliada a necessidade de incluir a atividade de Revisão/Consolidação da tarefa tradutória (apesar de ela não existir no modelo original da 
abordagem 'Ler para Aprender'). Nessa etapa, os participantes podiam apresentar suas retextualizações, discutir suas escolhas com o grupo (defendendo-as ou, até mesmo, mudando de opinião ao ouvir outras sugestões). Então, tornou-se uma etapa importante por propiciar a análise dos textos já traduzidos e o compartilhamento de informações e ideias surgidas durante a realização da tarefa, sendo, portanto, também considerada um momento de aprendizagem. A base para a adaptação foi o modelo de tradução de Alves (2005), que propõe três fases na atividade tradutória: orientação, redação e revisão. O Quadro 1 sintetiza a adaptação.

\section{Quadro 1 - Estratégias pedagógicas e aspectos textuais trabalhados}

\begin{tabular}{|c|c|}
\hline Estratégias & Atividades propostas \\
\hline $\begin{array}{l}\text { Preparação para } \\
\text { Leitura } \\
\text { (Fase: orientação do } \\
\text { processo tradutório) }\end{array}$ & $\begin{array}{l}\text { Etapa realizada em grupo } \\
\text { sobre o reconhecimento do } \\
\text { gênero e da estrutura } \\
\text { genérica dos textos fonte e } \\
\text { alvo, das variáveis do } \\
\text { contexto de situação social } \\
\text { em que circularam e dos } \\
\text { processos sociossemióticos } \\
\text { que realizam. }\end{array}$ \\
\hline $\begin{array}{l}\text { Leitura Detalhada/ } \\
\text { Preparação para a } \\
\text { Retextualização } \\
\text { (Fase: orientação do } \\
\text { processo tradutório) }\end{array}$ & $\begin{array}{l}\text { Etapa realizada em grupo, } \\
\text { incluindo a leitura dos textos } \\
\text { fonte e análise dos } \\
\text { elementos que constroem a } \\
\text { sua tessitura no âmbito das } \\
\text { orações, dos complexos } \\
\text { oracionais, dos parágrafos e } \\
\text { dos textos como um todo, } \\
\text { sendo os elementos dos } \\
\text { sistemas de coesão } \\
\text { estrutural - Temas } \\
\text { tópicos/ideacionais, } \\
\text { interpessoais e textuais e } \\
\text { suas realizações, } \\
\text { progressão temática -, e } \\
\text { coesão não estrutural - } \\
\text { gramatical e lexical -, vistos } \\
\text { de forma imbricada, pois } \\
\text { ambos os sistemas } \\
\text { contribuem para a formação } \\
\text { do tecido textual. }\end{array}$ \\
\hline $\begin{array}{c}\text { Reescritura/ } \\
\text { Retextualização } \\
\text { (Fase: redação do } \\
\text { texto-alvo) }\end{array}$ & $\begin{array}{l}\text { Etapa } \\
\text { individualmente: } \quad \text { tradução } \\
\text { de textos instanciadores dos } \\
\text { gêneros analisados, ou seja, } \\
\text { redação/produção do texto- } \\
\text { alvo. }\end{array}$ \\
\hline $\begin{array}{l}\text { Revisão/Consolidação } \\
\text { da atividade (Fase: } \\
\text { revisão do texto-alvo) }\end{array}$ & $\begin{array}{l}\text { Etapa realizada em grupo } \\
\text { por meio da discussão sobre } \\
\text { as escolhas feitas nas } \\
\text { traduções e da troca de } \\
\text { experiências entre os }\end{array}$ \\
\hline
\end{tabular}

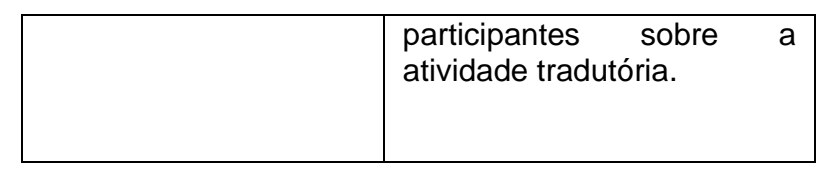

Fonte: Adaptado de Vieira (2018, p. 98)

Por meio dessa metodologia, foi proporcionado aos participantes um ensino interativo, teórico-prático, com discussões, troca de ideias e experiências, fomentando sua conscientização sobre as escolhas e ajudando-os a lidar com textos em relação de tradução, com uma visão mais ampla acerca dos diversos aspectos que envolvem os textos.

O corpus é constituído por dados coletados das atividades de análise de textos e de tradução e dos relatos da experiência pedagógica dos participantes. A coleta foi realizada em três momentos distintos da intervenção. A primeira coleta, feita antes do estudo (via Pré-teste e entrevista inicial), buscou avaliar o nível inicial de desenvolvimento da subcompetência bilíngue dos participantes e da sua capacidade de metarreflexão inicial quanto aos aspectos textuais a serem abordados e sua aplicação na análise e produção de textos em atividade tradutória. A segunda, no decorrer do estudo (via atividades didáticas de análise e de tradução de textos), objetivou a aplicação dos conteúdos discutidos e a avaliação do ensino/aprendizagem e do desenvolvimento de habilidades relacionadas à atividade tradutória e, ainda, a necessidade de possíveis ajustes na abordagem e/ou nos conteúdos. A terceira, no final do estudo (via Pós-teste e entrevista final), investigou indícios da possível ocorrência de desenvolvimento da subcompetência bilíngue e da capacidade metarreflexiva dos participantes sobre o conhecimento relativo aos aspectos textuais estudados e sua aplicação na análise e produção de textos em atividade tradutória. Nessas análises, a tradução foi considerada como produto e processo tradutórios.

Mesmo a abordagem pedagógica 'Ler para Aprender' não tendo sido o foco da pesquisa, ela foi avaliada pelos participantes após a conclusão da intervenção, visto que foi usada para viabilizar o ensino dos conteúdos selecionados. Então, apresentamos também alguns recortes das respostas dos 
participantes nas entrevistas finais, nas quais eles apontam as contribuições da referida abordagem para sua aprendizagem. O Quadro 2 apresenta parte do roteiro da entrevista final.

\section{Quadro 2 - Roteiro da entrevista final}

\begin{tabular}{|c|}
\hline $\mathbf{L}$ \\
\hline $\begin{array}{l}\text { Qual é a sua opinião sobre o estudo desenvolvido } \\
\text { durante esta disciplina, ou seja, o seu grau de } \\
\text { envolvimento com a disciplina e as dificuldades que } \\
\text { você teve com o conteúdo apresentado e as atividades } \\
\text { propostas? }\end{array}$ \\
\hline $\begin{array}{l}\text { Você acha que o conhecimento dos aspectos textuais } \\
\text { estudados nesta disciplina: conhecimentos } \\
\text { extralinguísticos (relação texto-contexto, noções de } \\
\text { gênero) e linguísticos (sistema de coesão não } \\
\text { estrutural e estrutural: sistema de tema) são úteis para } \\
\text { as suas atividades como leitor, produtor de texto e/ou } \\
\text { tradutor? }\end{array}$ \\
\hline $\begin{array}{l}\text { gidas na atividade tradutória } \\
\text { adas por este estudo (leitura, } \\
\text { rita tradutória), revisão textual, }\end{array}$ \\
\hline $\begin{array}{l}\text { Poderia explicar como ou por que esses } \\
\text { conhecimentos podem ajudar na atividade tradutória? } \\
\text { Em que fases do processo tradutório eles poderão }\end{array}$ \\
\hline
\end{tabular}

5. Comentário livre

Fonte: Adaptado de Vieira (2018).

Nessa entrevista, os participantes responderam perguntas sobre seu envolvimento e suas dificuldades com as atividades realizadas e a contribuição dos conhecimentos desenvolvidos para a atividade tradutória. Além disso, foram convidados a fazer um comentário livre ou apresentar sugestões para intervenções futuras. $\mathrm{Na}$ ocasião, foram lembrados de que deveriam se sentir à vontade para expressar sua opinião. Apresentamos, a seguir, a análise de parte dos seus relatos, nessa entrevista, sobre a intervenção pedagógica.

\subsection{Apresentação e Discussão de Resultados}

Analisando os comentários dos participantes na entrevista final, podemos inferir que as atividades práticas de análise do texto-fonte (discussão prévia sobre seus aspectos extralinguísticos e linguísticos), seguida do planejamento da tradução, ajudam o tradutor a desenvolver competência tradutória. Vale lembrar que todas as ações didático-pedagógicas em sala de aula foram realizadas no âmbito da nossa versão adaptada do modelo 'Ler para Aprender'.

Como defende P1 (na resposta à pergunta 4), o aluno passa a pensar nos Temas, nos Sujeitos, a entender que pode "recriar um texto de uma forma diferente, mas que [faça] o mesmo sentido que o original [...]". Também P3 (em resposta à pergunta 1) afirma que o conteúdo da disciplina fez com que ela visse o texto de uma outra ótica e também que, ao pegar um texto para traduzir, a fez "pensar no tipo, sobre o que [..] poderia mudar, poderia usar outras formas". Esse mesmo participante (P3), em resposta à pergunta 2, confirma que os conteúdos ensinados ajudam na leitura, tendo passado "a analisar o texto [previamente] [...] a ver diferente [...]". Já P2, ao responder à pergunta 2, defende que os conhecimentos extralinguísticos e linguísticos desenvolvidos (via estratégias pedagógicas da abordagem 'Ler para Aprender') ajudam na tradução, ao afirmar que:

[...] ajuda sim, inclusive quanto ao dividir o texto, ao separar as partes [P: estágios], também quando você divide em Tema e Rema, separando o componente verbal do nominal e encontrando as coisas que... meio que definem o texto. Fica bem mais fácil pra você entender o texto e pra que você consiga traduzir o texto (P2).

$\mathrm{Na}$ resposta à pergunta 4 , esse mesmo participante demonstra em que fase do processo tradutório esses conhecimentos influenciam. Pode-se visualizar o caminho que ele adotou ao realizar a tarefa tradutória, seguindo as estratégias da metodologia 'Ler para Aprender'.

[...] quando você meio que divide o texto, você meio que vai escolher o seu rumo que você vai seguir e como você vai usar e qual o alvo daquele texto, o que você está vendendo no seu produto, certamente. [P: Você analisa tudo pra depois traduzir?] sim, exatamente (P2).

Portanto, o relato de P2 indica que ele se apropriou desses pressupostos e estratégias de análise de textos (orientadas pela metodologia 'Ler 
para Aprender') como ferramentas para a fase de orientação (interpretação do texto-fonte e preparação para a retextualização do texto-alvo) do processo tradutório. Nessa perspectiva, em suas respostas à maioria das perguntas, P4 enfatiza a importância de trabalhar teoria e prática juntas. Vejamos esse trecho em resposta à pergunta 4 , no qual ele afirma que

[n]essas aulas a gente teve muito isso, a parte teórica, mas também teve a parte prática. [P: aplicação?] É o aplicar é importante porque, por exemplo, se a gente ficar tentando fazer isso sem uma orientação, a gente pegar um texto e começar a traduzir sem ver essas orientações, termina deixando passar muita coisa. Esses textos que a gente pegou que eram anúncios, não era só ver o texto em si, mas até mesmo as cores, o tipo, a empresa que está fazendo. Tudo influi. Então, a tradução vai além do texto [...] (P4).

Para ele, estudar a teoria e aplicar na tarefa tradutória ajuda a desenvolver competências. Ao responder a pergunta 3, enfatiza a importância da fase de orientação ('Preparação para Leitura, 'Leitura Detalhada' e 'Preparação para Retextualização') e destaca a análise de traços do contexto de situação, salientando o que deve ser feito antes de se começar a traduzir, por conta das diversas influências que um texto sofre. Vejamos a seguir:

[...] ajudou na fase de orientação, que é essencial. Acho que você tem que ter um certo cuidado, levar um certo tempo na orientação porque você tem que saber que texto é esse, pra quem ele se destina, pra você entender os vários elementos que envolvem o texto, tanto dentro como fora, pra depois começar a traduzir e aí, depois, na tradução, você tem mais condição [...] (P4).

Essas afirmações dos participantes estão em consonância com Rose (2007) e Martin e Rose (2007) quando destacam a importância da introdução das características gerais do gênero e dos estágios que o compõem, as fases e as mensagens contidas nas orações de cada uma no texto que instancia o gênero, defendendo também que o aprendiz precisa reconhecer o gênero através das variáveis do contexto de situação: campo, relações e modo do discurso. Nessa ótica, Halliday e Matthiessen (2014) enfatizam que, como a língua, o contexto também é funcional. Dessa relação texto-contexto resultam diferenças e similaridades entre os textos (HALLIDAY; 1989) e, daí, sua relevância para o desenvolvimento de habilidades de leitura e produção textual.

Faz-se necessário lembrar aqui que os conceitos citados pelos participantes, como fase de orientação/planejamento, referem-se às atividades de 'Preparação para Leitura', 'Leitura Detalhada' e 'Preparação para Reescritura' da metodologia 'Ler para Aprender', que, no nosso modelo adaptado de Rose e Martin (2012), correspondem à fase de orientação do processo tradutório (Figura 4 e Quadro 1).

Ao fazer um comentário livre, o participante P2 destaca a importância da atividade de "Revisão/Consolidação da tarefa tradutória. Vejamos o comentário.

[...] poderia trazer mais coisas pra [...] gente comparar na aula [...] apesar de ser uma coisa bem sistemática a cadeira, cada um fazia de um jeito diferente e era bem legal ver como cada um fazia (P2).

Entendemos que esse também é um momento de aprendizagem para o grupo por conta da discussão final sobre a tarefa, ou seja, principalmente pela oportunidade de compartilhamento das experiências de cada participante. Já os comentários livres de P3 e P4 destacam principalmente a metodologia. Vejamos a seguir:

[...] talvez trabalhar mais com a metodologia na prática, fazer mais atividades $[\ldots]$ (P3).

[...] acho assim que esse tipo de disciplina é importante pra academia, eu acho que tem que ter mais coisa do tipo, envolvendo teoria e prática, envolvendo projetos de pesquisa nesse campo, eu acho que precisa (P4).

Assim, podemos afirmar que os resultados desse estudo indicam que a metarreflexão foi desenvolvida em decorrência do incremento da subcompetência bilíngue dos participantes quanto aos aspectos extralinguísticos e linguísticos dos textos. Nesse sentido, as estratégias adotadas da abordagem 'Ler para Aprender' destacaram-se como ferramentas relevantes para a análise dos textos (fonte e alvo). 
Portanto, depreendemos que o modelo adaptado dessa metodologia foi capaz de levar os participantes aos resultados satisfatórios relatados.

\section{CONSIDERAÇÕES FINAIS}

A intervenção pedagógica visando o desenvolvimento da subcompetência bilíngue e metarreflexão de tradutores em formação sobre aspectos relativos à tessitura textual foi desenvolvida por meio da abordagem sistêmico-funcionalista 'Ler para Aprender' (ROSE; MARTIN, 2012). Enfatizamos que, apesar de o estudo não ter tido como foco investigar essa metodologia, os comentários dos participantes na entrevista final indicam a eficácia de suas estratégias. Essa abordagem proporcionou um ensino teórico-prático e interativo, em que conhecimentos, estratégias e experiências foram discutidas e compartilhadas, levando ao enriquecimento das habilidades do grupo.

$\mathrm{Na}$ entrevista final, os participantes falaram sobre as dificuldades enfrentadas durante a disciplina, em relação ao conteúdo, mas argumentaram que conseguiram esclarecer dúvidas e consolidar conhecimentos úteis para a atividade tradutória. Os resultados da análise dos seus relatos apontam que a intervenção Ihes proporcionou ferramentas para olhar os textos sob uma nova perspectiva, tratando dos aspectos linguísticos e extralinguísticos. Eles afirmaram que, a partir desse estudo, passaram a fazer uso dos conceitos abordados nas atividades de análise e de tradução de textos e a planejar melhor a atividade tradutória, dedicando mais tempo à fase de orientação do processo tradutório por terem entendido melhor a sua importância. $\mathrm{Na}$ verdade, eles se referem às atividades de 'Preparação para Leitura', 'Leitura Detalhada' e 'Preparação para Reescritura' no modelo adaptado, para a atividade tradutória, da metodologia 'Ler para Aprender' (ROSE; MARTIN, 2012). Eles também defendem que o estudo desses conteúdos aplicados à tradução por meio das atividades pedagógicas teórico-práticas contribuiu para o desenvolvimento de suas habilidades de leitura, produção e revisão de textos, proporcionando mais domínio da tarefa tradutória, tendo sido as discussões na fase de orientação relevantes para uma visão mais crítica dos textos e da atividade tradutória (metarreflexão).

Portanto, defendemos que as estratégias pedagógicas da metodologia 'Ler para Aprender' são ferramentas úteis para o ensino/aprendizagem por promover a interação e, consequentemente, o compartilhamento de informações. Por meio delas, foi proporcionada aos participantes a oportunidade de desenvolver conhecimentos e habilidades e uma visão mais crítica dos textos através da análise/investigação, compartilhamento de conhecimentos e prática, o que contribuiu para o incremento de subcompetência bilíngue e capacidade metarreflexiva relativa aos aspectos abordados no lidar com textos em relação de tradução.

\section{Referências}

ALVES, Fábio. Ritmo Cognitivo, Meta-reflexão e experiência: parâmetros de análise processual no desempenho de tradutores novatos e experientes. In: PAGANO, Adriana; MAGALHÃES, Célia; ALVES, Fábio. (Orgs.). Competência em tradução: cognição e discurso. Belo Horizonte: Editora UFMG, 2005. 311 p. p. $109-152$

CHRISTIE, Frances. Developing and implementing genre-based pedagogy: a systemic functional linguistic perspective. Caminhos em Linguística Aplicada v. 4. n.1, p. 1-21, 2011. Disponível em: www.unitau.br/caminhosla. Acesso em: 26 mar. 17.

HALLIDAY, Michael Alexander Kirkwood; MATTHIESSEN, Christian. Halliday's introduction to functional grammar. 4th ed. Ney York: Routledge, 2014. $786 \mathrm{p}$.

HALLIDAY, Michael Alexander Kirkwood. Language theory and translation practice. Rivista internazionale di tecnica della traduzione, $\mathrm{nr} 0$ (Pilot issui). Università di Trista, p. 15-25, 1992.

HALLIDAY, Michael Alexander Kirkwood. Part A. In: HALLIDAY, Michael A. Kirkwood; HASAN, Ruqaiya. Language, context, and text: aspects of language in a social semiotic perspective. 2nd ed. Oxford: Oxford University Press, 1989. 126 p. p. 1-49.

HURTADO ALBIR, Amparo. A aquisição da competência tradutória: aspectos teóricos e didáticos. In: PAGANO, Adriana; MAGALHÃES, Célia; ALVES, Fábio. (Orgs.). Competência em tradução: cognição e discurso. Belo Horizonte: Editora UFMG, 2005. 311 p. p. 19-57. 
KIM, Mira. Translation error analysis: a Systemic Functional Grammar approach. In: COFFIN, Caroline; LILLIS, Theresa.; KIERAN, Hallaran (Eds). Applied Linguistics methods: a reader: Systemic Functional Linguistics, Critical Discourse Analysis and Ethnography. London: Routledge, 2010. 273 p. p. 8494.

MAGALHÃES, Célia; ALVES, Fábio. Investigando o papel do monitoramento cognitivo-discursivo e da meta-reflexão na formação de tradutores. Cadernos de tradução, Florianópolis, n. 17, p. 71-127, abr. 2006.

MARTIN, James R; ROSE, David. Interacting with text: the role of dialogue in learning to read and write. Foreign Studies Journal, Beijing, v. 4, n. 5, p. 66-80, 2007.

MARTIN, James R; ROSE, David. Designing literacy pedagogy: scaffolding democracy in the classroom. In: HASAN, Ruqaiya; MATTHIESSEN, Christian; WEBSTER, Jonathan J. (Orgs.). Continuing discourse language: a functional perspective. v. 1. London: Equinox Publishing Ltd. 2005. 501 p. p. 251-280.

MARTIN, James R. English text: system and structure. Philadelphia: John Benjamins Publishing Company, 1992. 620 p.

MATTHIESSEN, Christian. The environments of translation. In: STEINER, Erich; YALLOP, Colin (Eds.). Exploring translation and multilingual text production, beyond content. New York: Mouton de Gruyer, 2001. 336 p. p. 41-124.

MUNDAY, Jeremy Spencer. Introducing translation studies: theories and applications. 2nd ed. London: Routledge, 2008. 236 p.

PACTE. Building a translation competence model. In: ALVES, Fábio (Ed.). Triangulating translation: perspectives in process oriented research. Amsterdan: John Benjamins, 2003. 163 p. p. 43-66.

PAGANO, Adriana. Modelagem sistêmico-funcional da tradução e da produção textual multilíngue. 2012. 233 p. Tese (Concurso Público de Provas e Títulos para preenchimento de vaga para a classe de Professor Titular na área de Estudos Linguísticos) Faculdade de Letras da Universidade Federal de Minas Gerais. Belo Horizonte, 2012.

ROSE, David; MARTIN, James R. Learning to write, reading to learn: genre, knowledge and pedagogy in the Sydney School. Sheffield, United Kingdom: Equinox Publishing, 2012. 368 p.

ROSE, David. Reading genre: a new wave of analysis. In: Linguistics and the human sciences, p. 1-30, 2007. Disponível em: www.researchgate.net/publication/254011813_Readin g_Genre_A_New_Wave_of_Analysis. Acesso em: 17 nov. $202 \overline{0}$.

VASCONCELLOS, Maria Lúcia Barbosa de. PAGANO, Adriana. Explorando interfaces: Estudos da Tradução, Linguística Sistêmico-Funcional e Linguística de
Corpus. In: ALVES, Fábio; MAGALHÃES, Célia, PAGANO, Adriana (Orgs.). Competência em tradução: cognição e discurso. Belo Horizonte, MG: Editora da UFMG, 2005. 311 p. p. 177-208.

VIEIRA, Teresinha Penaforte. Estudo sobre a subcompetência bilíngue e a metarreflexão de tradutores em formação sobre questões de tessitura textual: uma intervenção pedagógica baseada na LSF. 2018. 275p. Tese (Doutorado em Linguística Aplicada) - Centro de Humanidades, Universidade Estadual do Ceará. Fortaleza, 2018.

\section{COMO CITAR ESSE ARTIGO}

VIEIRA, Teresinha Penaforte; PRAXEDES FILHO, Pedro Henrique Lima. Intervenção pedagógica para 0 desenvolvimento de habilidades de tradutores em formação sobre questões de textualidade via abordagem Ler para Aprender. Signo, Santa Cruz do Sul, v. 46, n. 86, maio 2021. ISSN 1982-2014. Disponível em: $<$ https://online.unisc.br/seer/index.php/signo/article/view/159 81> doi:https://doi.org/10.17058/signo.v46i86.15981. 